\title{
A Review on Devulcanization of Waste Tire Rubber
}

\author{
Ali Gursel ${ }^{1}$, Enes Akca ${ }^{2}$, Nuri Sen ${ }^{1}$ \\ ${ }^{1}$ Departement of Mechanical Engineering, Faculty of Engineering, Duzce University \\ ${ }^{2}$ Departement of Mechanical Engineering, Faculty of Engineering and Natural Sciences, International University of Sarajevo
}

Article Info
Article history:
Received Apr $17^{\text {th }}, 2018$
Revised September $24^{\text {th }}, 2018$
Accepted Octobar $15^{\text {th }}, 2018$

Keyword:

Waste tire rubber

Recycling

Devulcanization

\begin{abstract}
Rubber has become an indispensable material for the technological development of civilization, including simple balloon and complex rocket propellant. Rubber Industry worldwide is using on an average $50 \%$ of raw materials. These materials were mostly petroleum-based, except natural rubber (NR), steel cord and bead wire. Using of these petroleum-based raw materials not only depletes natural resources, but also produces more extreme environmental hazards. The waste tire rubber problem is of great magnitude and has far reaching environmental and economic implications. There are some ways for recycling of rubber, such as reclaiming technology, surface treatment, grinding and pulverization technology, devulcanization technology. Methods of devulcanizing rubber (or elastomers) have been researched almost since the time of the discovery of the rubber/sulfur vulcanization process. By devulcanization process the cross-links in the structure of rubber are broken and devulcanized rubber can be revulcanized into a raw material for rubber industry, which is a highly valued form of waste rubber. This study provides a review of the recent advances in understanding of methods of recycling rubber and claims that the capacity of thermomechanical and mechanochemical devulcanization methods of recycling waste tire rubber can be improved in future studies.
\end{abstract}

\section{Corresponding Author:}

Ali Gursel,

Departement of Mechanical Engineering,

Duzce University,

Düzce Üniversitesi Konuralp Yerleşkesi, Konuralp Merkez/Düzce 81620, Turkey.

Email: aligursel@duzce.edu.tr

\section{Introduction}

The annual consumption of natural rubber is more than 15 million tons, and the output of rubber products is more than 31 million tons worldwide [1]. With the increasing demand for more rubber products, a lot of waste rubber is produced every year in the world. The main source of waste rubber products is discarded waste tires, rubber pipes, rubber belts, rubber shoes, edge scraps, and waste products that are produced in the rubber processes and others [2]. The handling of such large volumes of discarded elastomeric materials poses a serious environmental problem that must be faced by the scientific community. As the options of disposals such as landfills, stockpiling, and incineration become increasingly less viable due to cost and environmental concerns, a wide variety of reclaiming methods [3-5] have been investigated to recycle waste rubbers. The methodologies developed have enabled reutilization of waste rubber products especially tires only partially. The need for total recycling requires continuous development of alternative methods.

The devulcanization and reutilization of cross-linked elastomers are very difficult because of the threedimentional network. This network makes the material insoluble and nonmelting. The yearly global consumption of vulcanized elastomer is 17.2 million tons [6] of which approximately $39 \%$ is natural rubber and the remaining $61 \%$ consists of other synthetic rubbers. To improve the properties of rubber vulcanization is required [7]. 
Once the rubber is cross-linked, it becomes very difficult to recycle. Physically and chemically many attempts were made to reuse the vulcanized rubber. The physical process consists of mechanical [8-10], thermomechanical [11], cryomechanical [12], microwaves [13], and ultrasound [14] methods. In chemical reclaiming processes different types of disulfide [15], thiol [16], and catalyst are used. However, currently no technique exists that revertses maximum mechanical property of vulcanized natural.

\section{Structure of Tires}

For recycling of waste tires and convert scrap tires into a useful product, the complexity of the tire must be understood, including its various types and compositions. Different types include passenger (such as the new sophisticated run flat type illustrated in Figure 1), SUV, truck and bus, agricultural, and off-the-road (OTR). The general composition of tires is noted in Table 1 [17].
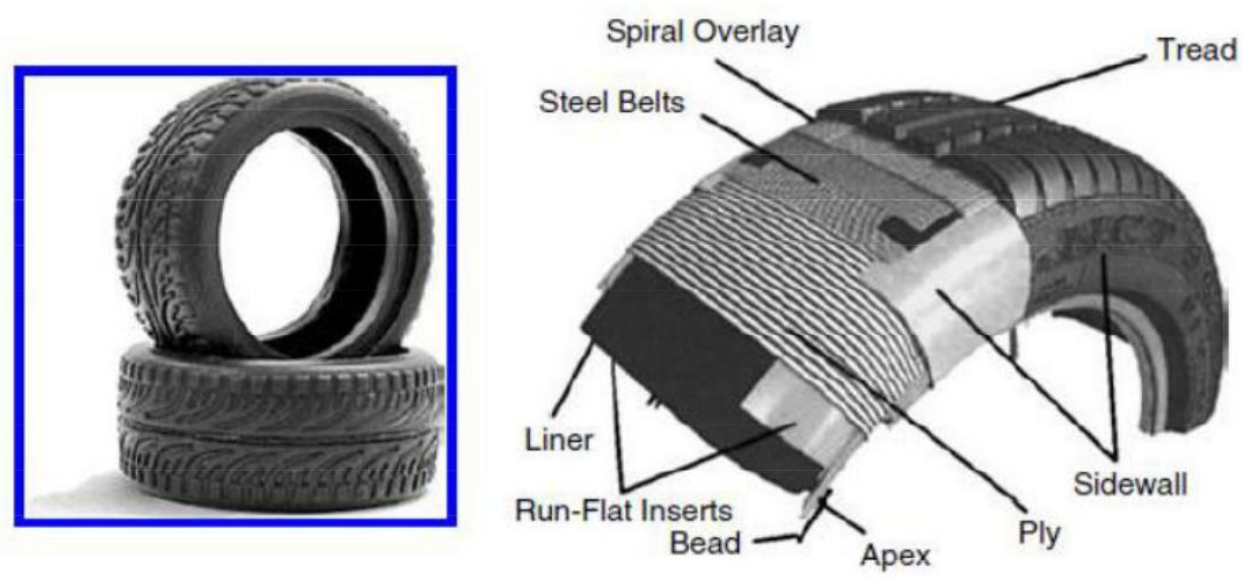

Figure 1. Typical passenger tire and components of a run flat tire

Table 1. General Composition of a Tire

\begin{tabular}{||l|c||}
\hline The Materials of Construction & $\begin{array}{c}\text { Approximate Weight } \\
\text { Percent \% }\end{array}$ \\
\hline \hline Rubber hydrocarbon composition (RHC) & 48 \\
\hline Carbon black and silica & 22 \\
\hline Metal reinforcements & 15 \\
\hline Oil, antidegradants, wax, stearic acid, etc. & 8 \\
\hline Fabric & 5 \\
\hline Zinc oxide $(\mathrm{ZnO})$ & 1 \\
\hline Curing agents & 1 \\
\hline Total & 100 \\
\hline
\end{tabular}

Concerning a tire's composition, the rubber components can vary widely. Passenger types tend to be high in styrene butadiene rubber (SBR), a general purpose rubber. Truck tires tend to be a 50:50 blend of SBR and natural rubber (NR). OTR types are composed mainly of NR, which has excellent fatigue resistance and high strength; these tires are mainly designed for cut and chip ruggedness. Knowing the tire source - the raw material - and its relation to the intended application can play a major role in the success or failure of the processed TDM. Consider a situation where crumb rubber material (CRM) is designated for an asphalt application. If the initial test work was with OTR rubber but the tire processor shipped passenger type CRM instead, the result could be disastrous at the paving site. Let's analyze why such a mix-up could be a disaster. CRM from OTR tires or NR will dissolve more readily in a given asphalt cement (AC) at lower temperatures and will provide low-temperature performance for a given climate, such as very cold weather. The passenger tire CRM, on the other hand, will require higher blending temperatures and be more suitable for hot climates. This dichotomy could produce very different results. Today, the Federal Highway Administration (FHWA) Superpave program has developed very specific performance tests to meet highway pavement criteria. Switching CRM source types from initial investigations could seriously hamper a highway pavement construction project. If this happened, significant penalties could be assessed and the processor's credibility 
and future projects could be jeopardized. It is therefore critical to know the source and composition of the CRM. Another example is the use of TDM in playgrounds. Bias tires that have the beads removed would be an ideal raw material for this application. However, with all tire types now containing steel cords, the liability issue becomes very critical. The wire contaminants, including the bead wires, must be completely removed and rendered as a non-issue when it comes to this application [17].

Trace amounts of wire powders left in powdered CRM for tire compounding applications can interfere with the cure mechanism, resulting in adverse effects to the performance of the final produced tires. It is the responsibility of the CRM processor to find or develop suitable tests for iron content. These test procedures should become part of the certificate of analysis (COA) and be agreed to by the end user, so no surprises occur. A general understanding of the chemical components in a tire is essential even when considering TDM materials as a soil amendment. Zinc oxide ( $\mathrm{ZnO}$, noted in Table 1) is a significant metal in TDM, along with other ingredients. These components can have the adverse effect of leaching into the soil or plants over time, under certain conditions of the various soil types. Preparation for the application, in accordance with the defined guidelines, needs to proceed the time of CRM procurement and continue through manufacturing (processing) to delivery at the end user's site [17].

\section{Recycling processes of waste tires}

The recycling of the waste tires and rubbers has been applying with verity of techniques. In the environmental perspective, dividing the materials and producing energy and devocalization processes to obtain the original rubber like unprocessed or virgin.

The topic of rubber recycling is drawing attention recently because of the stringent laws enacted world over to protect the environment. Adhikari et al [18] have given a comprehensive summary of all the processes involved in the reclaimation and recycling of waste rubber. The used automotive tires constitute the major source of waste rubber. The worldwide attempt in recycling waste tires is being carried out broadly in the following directions [19]:

(1) Production of ground rubber tire (GRT) powder and using it as filler in different rubber vulcanizates and in road paving

(2) Devulcanization or reclaiming of rubber powder and

(3) Incineration in power plants, cement kilns etc.

The GRT is produced by either ambient grinding or cryo-grinding processes [20]. A surface activated waste rubber powder [21] has been produced with a cross-linkable surface layer, which can be used as a partial or a total substitute of rubber compound.

Both physical and chemical processes are used to carry out the devulcanization or reclaiming of GRT. The powder is either subjected to shearing action in suitable equipment like extruder or two-roll mill and partially decrosslinked or to chemical action to give reclaimed material [22]. Physical processes involve the application of mechanical, thermo-mechanical, microwave or ultrasound energy to partially devulcanize the rubber.

\section{Results and Discussion}

According to the literatures and previous studies, the pyrolysis techniques are an option to recycle the waste rubbers by dividing the materials, producing energy and etc. However, it is better them to return back original structure by devulcavization process to use in exact field as in the beginning, which means it is a real recycling.

\subsection{Devulcanization of tire rubber}

Regarding the tire design and standardization of thermo-chemical shear extrusion (TCSE) process for decrosslinking of the waste ground rubber tire (GRT) powder by shearing it at high temperature $(1708 \pm 200$ $8 \mathrm{C}$ ) with and without devulcanising chemicals in a counter rotating twin screw extruder. The functions of the extruder are [22]:

(1) conveying the waste GRT vulcanizate

(2) shearing and heating of the GRT powder and

(3) devulcanisation. 
In a counter rotating twin-screw extruder, two screws lie side by side in a common barrel in a figure-of-eight pattern and rotate in the opposite directions. The material moves through the extruder as discrete solid particles getting devulcanized due to concerted thermal, chemical and mechanical action, and comes out as a soft, tacky solid plug.

Isayev et al [23-25] have developed a process using a continuous ultra-sonic reactor to devulcanize GRT powder, SBR, unfilled silicone rubber and carbon black filled rubber vulcanizates. Santos et al [26] used a similar ultrasonic reactor to devulcanize guayule rubber vulcanizate.

In the chemical reclaiming process, different chemical devulcanising agents like diphenyldisulphide, dibenzyl disulphide, diamyldisulphide [27-28], mercaptan, xylenethiol, iron oxide/phenyl hydrazine mixture etc. have been used for the treatment of scrap ground rubber powders at elevated temperature. De et al [29] reclaimed sulfur cured natural rubber vulcanizates using a vegetable product based on diallyldisulphide, which they called renewable resource material (RRM).Verbruggen et al [30] have studied the thermo-chemical action of diphenyl disulphide on sulfur vulcanized NR and EPDM vulcanizates and concluded that both main chain and crosslink scissions caused the network breakdown resulting in a recyclable powder.

The devulcanization process requires high energy [24] to break the -C-S-C- $(285 \mathrm{KJ} / \mathrm{mol})$, -C-S-S-C- $(268$ $\mathrm{KJ} / \mathrm{mol})$ or C-Sx-C- $(251 \mathrm{KJ} / \mathrm{mol})$ bonds. It is highly desirable that this energy is selectively directed towards the cross-link sites without the scission of the main-chain. It can be achieved by a simultaneous chemical, thermal and mechanical action at nominal shearing in a twin screw extruder (TSE). Recently, there are reports of depolymerisation reactions having been carried out in TSE [31]. Khait [32] has developed a process called Solid-State Shear Extrusion (SSSE) using a co-rotating twin screw extruder at ambient temperature to produce a recyclable rubber powder.

\subsection{Thermomechanical and mechanochemical devulcanization}

In the present study, over all devulcaniziation processes have been investigated and more focused on thermomechanical and mechanochemical devulcanization processes. The most recent mechanical devulcanization technic is the screw extruder method, which can be improved. Fang et al. [1], Klingensmith and Baranwal [33], Zelibor et al. [34], and Myhre and MacKillop [35] provided comprehensive summaries of processes that are being investigated or being used for recycling waste rubber. Recently, Maridass and Gupta [22] have developed a counter-rotating twin screw extruder (TSE) to devulcanize waste ground rubber tire for recycling [2]. The principle of screw extruder method is seen in the Figure 2 [36]. In this process, breakage of crosslinking points in the three dimensionally crosslinked vulcanizate occurs selectively under the controlled temperature and shearing action. The product obtained from waste rubber powder shows satisfactory mechanical properties applicable to new rubber compounds.

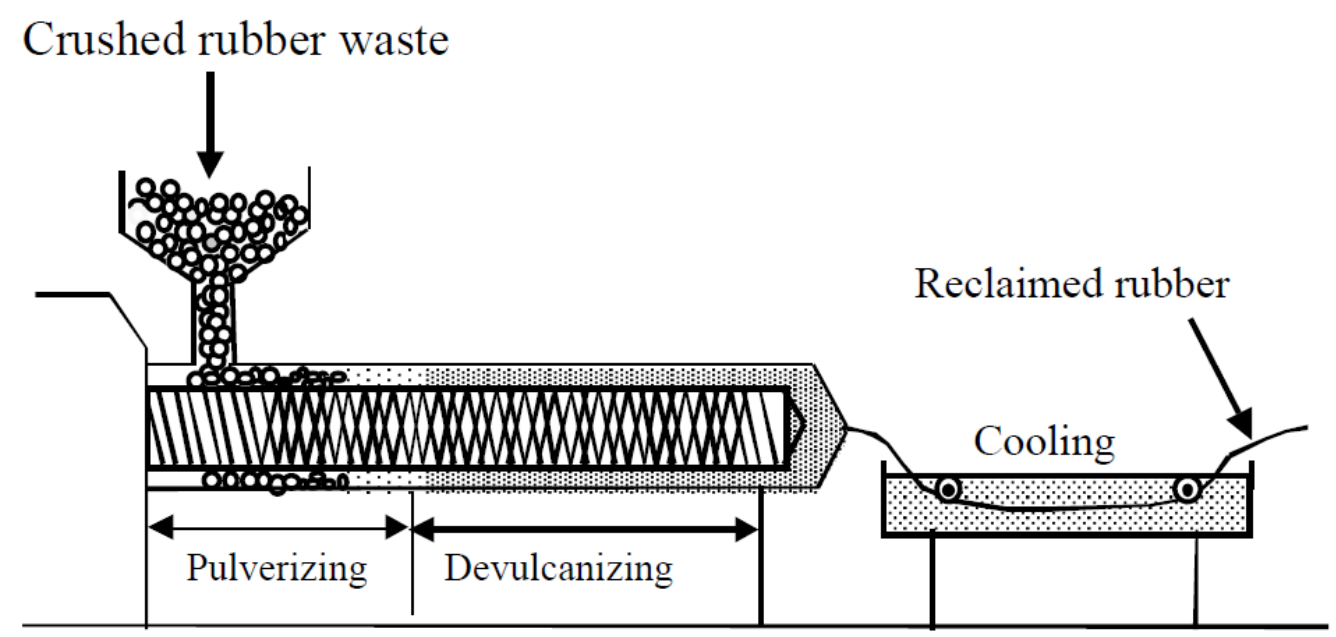

Figure 2. Screw extruder

Most of the reported studies on extruder optimizations [36, 37] were done by the one variable at a time (OVAT) experimental method, which means that only one parameter is changed while the remaining parameters were kept constant for a given set of experiments. In this case, it has been reported earlier [35] by OVAT method that extruder temperature and screw speed are the two main factors that influence the extent of devulcanization in TSE. The extruder performance can be optimized by establishing a functional relationship 
between the variables (screw speed and barrel temperature) and responses using response surface methodology as discussed in detail by Box [38] and Montgomery [39]. Derringer [40] has discussed elaborately the role of RSM in rubber compounding.

Chemically vulcanized natural rubber contains mono, di, and polysulfide linkage at the diene sites in a network structure [41]. So this cross-linked bond can be cleaved to devulcanize the rubber. According to Tobolsky et al. [42,43] this sulfur-sulfur cross-linked bond are the weakest of the chemical bonds [44]. Bond energies, DC_C (in cross-linked peroxide vulcanizate) is equal to $93 \mathrm{Kcal}=\mathrm{mol}$, DC_S_C (monosulfide crosslinked) is equal to 50-60 Kcal=mol, DC_S_S_C (disulfide cross-linked) is equal to $35 \mathrm{Kcal}=\mathrm{mol}$ and DC_S_S_S_C (polysulfide cross-linked) is equal to $27 \mathrm{Kcal}=\mathrm{mol}$. Hence, these sulfidic bonds can break easily by using temperature, pressure, and chemicals.

Only 20\%-25\% mechanical properties of vulcanized natural rubber were retained using diallyl disulfide as reported by De et al [45]. Tripathy et al. [46] developed a process called high pressure high temperature sintering that converts vulcanized rubber powder into usable rubber product. But this process reverts only $35 \%-40 \%$ of the mechanical properties. However, incorporation of small amount of organic disulfide, such as diaryl disulfide, with the vulcanized natural rubber allows greater than $65 \%$ of the original mechanical properties of the vulcanized natural rubber to be recovered $[47,48,49]$. In the previous studies incorporation of a small amount of organic disulfide, such as diaryl disulfide, with the vulcanized natural rubber greater than $65 \%$ of the original mechanical properties of the vulcanized natural rubber were recovered.

\section{Conclusion}

The literature shows that many researches have been focused on recycling of the waste tire, in order to obtain higher benefit from this enormous source of valuable materials and directly re-usage as virgin rubber in the field. However, there are no satisfied processed improved yet. It's needed to be improved the quality of recycled and devulcanized rubbers, to create mass recycling process, to simplify and decrease the investment and processing costs. For environmental perspective, recycling of the rubber material is an obligation. But on the other hand, especially during the pyrolysis or devuncanization process, the consumption of energy and chemicals and also investment of equipment are more likely higher than the value of waste tire rubber.

The researcher in the future studies needed to focus on increasing the process capacity of recycling rubber and find new technique to decrease of the consumptions. Based on reviewing the literature, it is thought that thermomechanical and mechanochemical devulcanization methods can be improved to decrease consumption of energy for processing and to increase the amount of devulcanized product with new approaches.

\section{References}

[1] Y. Fang, M. Zhan, Y. Wang, "The status of recycling of waste rubber," Materials and Design, vol. 22, pp. 123-127, 2001.

[2] B. Maridass, B. R. Gupta. "Process Optimization of Devulcanization of Waste Rubber Powder from Syringe Stoppers by Twin Screw Extruder Using Response Surface Methodology," Polymer Composites, vol. 29, pp. 1350-1357, 2008.

[3] S. E. Shimand, A. I. Isayev, "Ultrasonic Devulcanization of Precipitated Silica-Filled Silicone Rubber," Rubber Chemistry Technology, vol. 74, pp. 303-316, 2001.

[4] E. Bilgili, H. Arastoopour, B. Bernstein, "Analysis of Rubber Particles Produced by the Solid State Shear Extrusion Pulverization Process," Rubber Chemistry Technology, vol. 73, pp. 340-355, 2000.

[5] K. Fukumori, M. Matsushita, H. Okamato, N. Sato, Y. Suzuki, K. Takeuchi, "Recycling Technology of Tire Rubber, " JSAE Review, vol. 23, pp. 259-264, 2002.

[6] IRSG preliminary statistics; http://www.rubberstudy.com=STATS.htm

[7] G. K. Jana, C. K. Das, "Devulcanization of Natural Rubber Vulcanizates by Mechanochemical Process," Polymer-Plastics Technology and Engineering, vol. 44, pp. 1399-1412, 2005.

[8] Phadke; A. K. Bhattacharya, S. K. Chakraborty, S. K. De, " Studies of Vulcanization of Reclaimed Rubber," Rubber Chemistry and Technology, vol. 56, pp. 726-736, 1983.

[9] N. R. Braton, "Disposal and Reclamation of Scrap Rubber Tires," Waste Age, vol. 3, pp. 61, 1972. 
[10] N. R. Braton, J. A. Koutsky, "A New Recycling Technology: Compression Molding of Pulverized Rubber Waste in the Absence of Virgin Rubber," Chemical Engineering News, vol. 52, pp. 21-26, 1974.

[11] Harshaft, "Solid waste treatment technology," Environmental Science and Technology, vol. 6, pp. 412421, 1972.

[12] Phadke, S. K. De, "Use of cryoground reclaimed rubber in natural rubber," Conservation \& Recycling, vol. 9, pp. 271-280, 1986.

[13] S. R. Fix, "Microwave Devulcanization of Rubber," Elastomerics, vol. 112, pp. 38-40, 1980.

[14] Tukachinsky, D. Schworm, A. I. Isayev, "Devulcanization of Waste Tire Rubber by Powerful Ultrasound," Rubber Chemistry and Technology, vol. 69, pp. 92-103, 1996.

[15] L. B. Jr. Tewksbury, L. H. Howland, Can. Patent 2 469-529, 1949.

[16] E. F. Sverdrup, J. Elgin, C.U.S. Patent 2 415-449, 1947.

[17] M. W. Rouse, "Quality Performance Factors for Tire-Derived Materials," Chapter 2, Taylor \& Francis Group, 2005.

[18] Adhikari, D. De, S. Maiti, "Reclamation and recycling of waste rubber," Progress in Polymer Science, vol. 25, pp. 909-948, 2000.

[19] Klingensmith, "Recycling, production and use of reprocessed rubbers," Rubber World, vol. 203, pp. 16, 1991.

[20] J. J. Leyden, "Cryogenic processing and recycling," Rubber World, vol. 203. pp. 28, 1991.

[21] W. Dierkes, "Solution to the rubber waste problem incorporating recycled rubber," Rubber World, vol. 214, pp. 25, 1996.

[22] B. Maridass, B. R. Gupta, "Recycling of Waste Tire Rubber Powder," Kautsch Gummi Kunstst, vol. 56, pp. 232-239, 2003.

[23] Isayev, J. Chen, A. Tukachinsky, "Novel Ultrasonic Technology for Devulcanization of Waste Rubbers," Rubber Chemistry and Technology, vol. 68, pp. 267-280, 1995.

[24] Diao, A. I. Isayev, V. Y. Levin, "Basic Study of Continuous Ultrasonic Devulcanization of Unfilled Silicone Rubber," Rubber Chemistry and Technology, vol. 72, pp. 152-164, 1999.

[25] K. Hong, A.I. Isayev, "Continuous ultrasonic devulcanization of carbon black- filled NR vulcanizates," Journal of Applied Polymer Science, vol. 79, pp. 2340-2348, 2001.

[26] Gonzalez-De Los Santos, F. Soriano-Corral, M. J. Lozano-Gonzalez, R. Cedillo-Garcia, "Devulcanization of Guayule Rubber by Ultrasound," Rubber Chemistry Technology, vol. 72, pp. 854861, 1999.

[27] C. Elgin, Can. Pat. 456,798 (1949).

[28] F. Sverdrup, U.S. Pat. 2,494,593 (1950).

[29] De, S. Maiti, B. Adhikari, "Reclaiming of Rubber by a Renewable Resource Material, Part 2, Comparative Evaluation of Reclaiming Process of NR Vulcanizate by RRM and Diallyl disulfide," Journal of Applied Polymer Science, vol. 73, pp. 2951-2958, 1999.

[30] M. A. L. Verbruggen, L. Van Der Does, J. W. M. Noordermeer, M. Van Duin, H. J. Manuel, "Mechanisms Involved in the Recycling of NR and EPDM," Rubber Chemistry Technology, vol. 72, pp. 731-740, 1999.

[31] Berzin, B. Vergnes, P. Dufosse, L. Delamare, "Modelling of peroxide initiated controlled degradation of polypropylene in a twin screw extruder," Polymer Engineering and Science, vol. 40, pp. 344-356, 2004.

[32] Khait, "Solid-state shear extrusion pulverization process," Rubber World, vol. 216, pp. 38, 1997.

[33] W. Klingensmith, K. Baranwal, " Recycling of Rubbers: An Overview," Rubber World, vol. 218, pp. 41-46, 1998. 
[34] J. L. Zelibor, M. H. Blumenthal, F. E. Timmons, "Recycling Scrap Tires into New Tires," Scrap Tire Management Council, Washington, D.C., 1992.

[35] Myhre, D. A. MacKillop, "Rubber Recycling," Rubber Chemistry and Technology, vol. 75, pp. 429-274, 2002.

[36] K. Fukumori, M. Matsustia, "Material Recyling Techology of Crosslinked Rubber Waste," R\&D Review of Toyota CRDL, vol. 38, pp. 39-47, 2003.

[37] Isayev, J. Chen, A. Tukachinsky, "Novel Ultrasonic Technology for Devulcanization of Waste Rubbers," Rubber Chemistry and Technology, vol. 68, pp. 267-280, 1995.

[38] P. Box, W. G. Hunter, S. S. Hunter, "Statistics for Experimenters: Design, Innovation, and Discovery," Wiley, New York, 1978.

[39] D. C. Montgomery, "Design and Analysis of Experiments," 5th ed., John Wiley and Sons, New York, 2001.

[40] C. Derringer, "Statistical Methods in Rubber Research and Development," Rubber Chemistry Technology, vol. 61, pp. 377-421, 1988.

[41] B. Saville, A. A. Watson, "Structural Characterization of Sulfur-Vulcanized Rubber Networks," Rubber Chemistry and Technology, vol. 40, pp. 100-148, 1967.

[42] A.V. Tobolsky, in Properties and Structures of Polymer, John Wiley and Son: New York, 1960.

[43] A.V. Tobolsky, in Polymer Science and Materials, Inter Science: New York, 1960.

[44] P. R. Dluzneski, "Peroxide Vulcanization of Elastomers," Rubber Chemistry and Technology, vol. 74, pp.451-492, 2001.

[45] D. De, S. Maity, B. Adhikary, "Reclaiming of rubber by a renewable resource material (RRM). II. Comparative evaluation of reclaiming process of NR vulcanizate by RRM and diallyl disulfide," Journal of Applied Polymer Science, vol. 73, pp. 2951-2958, 1999.

[46] R. Tripathy, J. E. Morin, D. E. Williams, S. J. Eyles, R. J. Farris, "A Novel Approach to Improving the Mechanical Properties in Recycled Vulcanized Natural Rubber and Its Mechanism," Macromolecules, vol. 35, pp. 4616-4627, 2002.

[47] K. Jana and C. K. Das, "Devulcanization of Natural Rubber Vulcanizates by Mechanochemical Process," Polymer-Plastics Technology and Engineering, vol. 44, pp. 1399-1412, 2005.

[48] A. Gursel, G. Y1ldiz, E. Akca, "Effects of Cooling Rate on Strength and Microstructure of Powder Metallurgy Superalloys," Periodicals of Engineering and Natural Sciences, vol. 5, pp. 251-255, 2017.

[49] O. Y. Bozkurt, O. Ozbek, A. R. Abdo, "The Effects of Nanosilica on Charpy Impact Behavior of Glass/Epoxy Fiber Reinforced Composite Laminates," Periodicals of Engineering and Natural Sciences, vol. 5, pp. 322-327, 2017. 